\title{
The students' coordinating conjunction acquisition order
}

\author{
Deby Irawan \\ debyirawan@outlook.com \\ Universitas Pendidikan Indonesia \\ Jl. Dr. Setiabudhi Nomor 299 Bandung, Indonesia
}

Received: February 27, 2017; $\quad$ Accepted: February 3, 2018; Published: March 2, 2018

\begin{abstract}
This study is aimed at uncovering the students' acquisition order of coordinating conjunction for then to seek the possible causes of such phenomenon. Quantitative approach with implicational scaling and qualitative approach with case study were employed with test, focused-group interview, and document analysis of some related textbooks as the instruments. A test consist of 70 questions about the usage of seven coordinating conjunctions in which each word is represented by 10 questions was given to the 13 students of eleventh grade of senior high school for the data collection related to the students' acquisition order. The documents were then analyzed through several steps as suggested by the expert. The results show that the students acquire "and", "so", "for", "but", "or", "yet", and "nor" as in order. The external factors which influence the order are the formal complexity of each conjunction and the lack of exposure of coordinating conjunction both in the teaching activity and textbooks. Thus, teachers are suggested to provide more explicit teaching on coordinating conjunction and necessary knowledge about the usage of each word. Also, book writers should provide ample exposure to give students more knowledge about the usage of those conjunctions in a meaningful context.
\end{abstract}

Keywords: coordinating conjunction, implicational scaling, second language acquisition, acquisition order

How to cite this paper: Irawan, D. (2018). The students' coordinating conjunction acquisition order. Journal on English as a Foreign Language, 8(1), 1-18 (doi: 10.23971/jefl.v8i1.541)

DOI: http://dx.doi.org/10.23971/jefl.v8i1.541 
In language, there are two aspects which are dependent one to another i.e. meaning and forms. A meaning can only be transmitted through forms as the carrier. Forms can have its function if a meaning is attached to it. In daily life, people constantly form the message they want to convey for then be communicated thought structured words to other people. Meanwhile, to understand one's utterance, people need to draw the meaning from the words used by the speaker. In language teaching, focus on meaning demands the teaching process to only use material that is meaningful as it reflects the daily use of the language. Focus on forms language teaching demands the teaching of language to only focus on the grammatical aspect of language. So, students understand the way a sentence or paragraph is formed.

It is an alternative option when focus on meaning and focus on forms teaching results were not satisfying (Farrokhi \& Talabari, 2014). By this approach, students will not only learn the structure of target language as in focus on forms approach, but also learn about the context of appropriate language use as in focus on meaning approach. In addition, in the acquisition of the lexical level of Indonesian students begins to use a word form which is different from western students (Dardjowidjojo as cited in Fauzi, 2012, p. 2).

In the case of making a fluid flow communication, a number of connecting words can be used. In a book Modern English: A Practical Reference Guide written by Marcella Frank, it is stated that conjunctions, as connecting words offer certain features which can be used by interlocutors to transfer meanings. It is a number of words which have no form characteristic. Their function is as a non-moveable structure unit which joins other units such as parts of speech, phrase or clause. By having the ability to use conjunction, someone will be able to transmit meaning in a seamless form.

The use of conjunction is the co-attached example of language form and meaning. A conjunction as a form has its own meaning in which one usage situation is different to other conjunctions. This condition emphasizes the necessity to learn language by using the focus on forms approach. While learning about the variety of conjunctions, the students also need to learn about the meaningful way to use the conjunction. Hence, the students will not only learn about the structure but also the meaning or situation in which the conjunction should or should not be used.

Conjunctions are divided into two categories based on the joined unit. Those are coordinating and subordinating conjunctions. However, in this research report the discussion only focuses on coordinating conjunction for it is the most frequently used conjunction in daily interaction. Coordinating conjunction joins structural unit that are grammatically equal. Each of the structural units is independent. Conjunction is always used between the 
clauses. However, if the clauses are more than two, the conjunction comes before the last unit.

There are seven conjunctions which are usually used. Those conjunctions are "and", "or", "nor", "but", "yet", "so", and "for". Among those conjunctions, "and", "or", and "but" are considered as the most commonly used conjunction rather than the rest of them (Shrives, 2014). These conjunctions are deliberated as the less complex coordinating conjunction since the meaning is closely related to daily use while the rest of them seem to be used in a more formal situation.

Related to the connection between meaning and form previously explained, in a book Let's write English written by Wishom and Burks, it is stated that each of the conjunctions has its own meaning and usage. The conjunction "and" is usually used to show augmentation. The other function includes to show that one idea is time sequenced and or the result of another. Meanwhile, "but" is usually used to show contrast, affirmative sense what the first part of the sentence implied, and even to connect two ideas with the meaning of "with the exception of" sense. The conjunction "or" and "nor" are basically also used to show contras, as the "but" conjunction. However, it can be used to show that only one possibility can be realized, to show the inclusive combination of alternative, and to show a refinement of the first clause. Especially for "nor", the usage usually accompanied by "neither".

The conjunction "yet" actually has a similar use with "but", that is to show contrast. However, the word "yet" seems to carry distinctiveness element that "but" cannot register. On the other hand, the word "for" sometimes is used as preposition. The function of "for" as coordinating conjunction is rarely found in daily occasion. It is used to show reason for the preceding clause. The meaning brought by using "for" is more serious than using "because" or "since". Have a quite similar usage to the "for" conjunction, the conjunction "so" is used to show reason. However, the clause arrangement is different. If clauses connected by "for" has an action + reason clause arrangement, the use of "so" has reason + action clause arrangement. The comprehensive explanation of each conjunctions' function is shown in Table 1.

The existence of knowledge of conjunctions in the students' mainframe is prerequisite before it comes to the usage. It means that one should acquire the information that such forms can be used to carry certain meaning. Especially for a non-native English speaker which is happened to be in a situation where English is not used as in daily communication, the process of acquiring such information can be in a hard position. 
Table 1. The Function and Example of each Coordinating Conjunctions

\begin{tabular}{|c|c|c|}
\hline No & Conjunction & Function and Example \\
\hline 1 & And & $\begin{array}{l}\text { - To show one idea is time sequenced to another. } \\
\text { Example: } \\
\text { "John insert a dime and choose a bottle of coke in the vending } \\
\text { machine." } \\
\text { - To show that one idea is the result of another. } \\
\text { Example: } \\
\text { "Mike read the weather forecast and decide to bring an } \\
\text { umbrella to the campus." } \\
\text { - To show that one idea is in contrast to another. It is frequently } \\
\text { replaced by but in the usage. } \\
\text { Example: } \\
\text { "Juanita is genius and Shakira has a pleasant personality." } \\
\text { - To show an element of surprise. It is frequently replaced by } \\
\text { yet in the usage. } \\
\text { Example: } \\
\text { "Jakarta is a huge city and crowded." }\end{array}$ \\
\hline 2 & But & $\begin{array}{l}\text { - To show a contrast that is unexpected in light of the first } \\
\text { clause. } \\
\text { Example: } \\
\text { "Jimmy lost a huge amount of money on the last trade, but he } \\
\text { still seems able to run his company." } \\
\text { - To show in an affirmative sense what the first part of the } \\
\text { sentence implied in a negative way. This usage frequently } \\
\text { replaced by on the contrary. } \\
\text { Example: } \\
\text { "Harper never waste his time for nothing, but used to play } \\
\text { game all day long." } \\
\text { To connect two ideas with the meaning of "with the exception } \\
\text { of" sense. } \\
\text { Example: } \\
\text { "Everybody but Taylor remember that the class was } \\
\text { dismissed." }\end{array}$ \\
\hline
\end{tabular}

\begin{tabular}{ll}
\hline 3 Or $\quad$ - & To show that only one possibility can be realized. \\
& Example: \\
& "You can keep crying all the night or you can move on." \\
- & To show the inclusive combination of alternative. \\
& Example: \\
& "We can buy more snack, or we can just eat this candy." \\
- & To show a refinement of the first clause. \\
& Example:
\end{tabular}




\begin{tabular}{|c|c|c|}
\hline & & $\begin{array}{l}\text { "UPI is the best university in Bandung, or so it seems to best in } \\
\text { Indonesia." } \\
\text { - To show a restatement or correction of the first part of the } \\
\text { sentence. } \\
\text { Example: } \\
\text { "There is no Intel core-i9 in this world, or so we have seen it by } \\
\text { now." } \\
\text { - To show a negative condition. } \\
\text { Example: } \\
\text { "Live free or die." } \\
\text { - To show a negative alternative. } \\
\text { Example: } \\
\text { "They must go by now or they will never make it." }\end{array}$ \\
\hline 4 & Nor & $\begin{array}{l}\text { It is used with other negative expressions. } \\
\text { Example: } \\
\text { 'This is not what I wanted to do, nor should you take my action as } \\
\text { a revenge.' }\end{array}$ \\
\hline 5 & Yet & $\begin{array}{l}\text { It is used to carry distinctiveness element that "but" can seldom } \\
\text { register. } \\
\text { Example: } \\
\text { "The visitor complained loudly about the heat yet they continued } \\
\text { to play golf every day." }\end{array}$ \\
\hline 6 & For & $\begin{array}{l}\text { It is used to show reason for the preceding clause. The meaning } \\
\text { brought by using "for" is more serious than using "because" or } \\
\text { "since". } \\
\text { Example: } \\
\text { "John thought he had a good chance to get the job, for his father } \\
\text { was on the company's board of trustees." }\end{array}$ \\
\hline 7 & So & $\begin{array}{l}\text { When clauses connected by "for" has an action + reason clause } \\
\text { arrangement, the use of so has different one that is reason + action. } \\
\text { Example: } \\
\text { "His father was on the company's board of trustees, so John } \\
\text { thought he had a good chance to get the job." }\end{array}$ \\
\hline
\end{tabular}

Indonesia is considered as the member of expanding circle countries in which English is learnt as a foreign language (Kachru, 2005). In Indonesian English classroom, it is learnt English as a foreign language (EFL) (Miftah, 2016, p. 2). English is mostly leant in classroom teaching and learning activities with a limited usage in the social interaction. The main exposure of English comes from books and materials used by the teachers. By this condition, the process of acquiring the language can be different. In consequences, the acquisition order of several language aspects can also be vary from other countries, not to 
mention if the country is considered as the member of different circle of English speaker.

In relation to the conjunction acquisition order and the limited exposure of language sample, the current condition in which the students exposure of English only come from books and materials delivered by the teachers, the consideration is related to whether or not the books and selected materials reflect the actual language use. It is related to the authenticity of the materials. Students' books are considered as commercial materials in which the materials are designed as a learning materials (Richards \& Schmidt, 2002). It is possible that the materials do not contain enough and fair amount of conjunction used in daily life. This matter emphasizes the usage of authentic materials in language teaching to provide students with a natural language in focus on forms language teaching.

In the field of second language acquisition, the process of acquiring a language might have certain patterns. It deals with the phenomenon that some language components could be acquired faster than the others. A number of aspects might alter the formation of the pattern. A theory so called "discourse hypothesis" can be used to explain the phenomenon. It looks at the structure of texts' discourse in which utterances appear (Gass \& Selinker, 2008). Also, it is important to find the alternative ways such as enrichment programs for students at the beginning of language acquisition (Umami, 2011, p. 200).

Bardovi-Harlig as cited in Gass and Selinker (2008) departs from the discourse hypothesis theory as he proposes three possible explanations for a phenomenon that students acquire "will" before "going to". The first is related to formal complexity. It explains that "will" is less complex than "going to". The assumption is supported with a claim which says that there is a tendency of people to use less complex, more universal, and less marked forms in all settings (Romaine, 2003). The second one is related to the perception that "will" is perceived as lexical marker. It fits with the observation result that lexical markers often precedes grammatical marking in the process of second language acquisition (Gass \& Selinker, 2008). This assumption is also supported by a fact that in English, the number of lexical items exceeds that of grammatical entities (Lengyel, Navracsics, \& Szilagyi, 2007). Then the third one is related to a principle so called one-to-one principle. This principle stated that one form only can express one single meaning. In another source, it is also known as one formone function principles (Lieven \& Tomasello, 2008). If a form then have a possibility to carry more than one function, it could be hard for students to digest compared to a form which only carries one function.

By referring to the table one, it can be theoretically stated that the coordinating conjunction acquisition order of the students can also be vary. In 
the term of formal complexity, it seems that some of the coordination conjunctions are more complex that the other. It can be seen that the "nor" conjunction require the use in which two negative clauses are presented in a single sentence. The usage also requires the presence of additional word, "neither". The "for" and "so" also seems to be complex since two of them carry a similar function but is a different clause formation. It appears that students will firstly acquire the "and", "but" and "or" which are less complex than the other conjunction.

Then in the term of lexical marker, it seems that the students will not found it problematic. However the "for" is usually used as a preposition. Even if it is not the matter of lexical marker, the different usage of a word across part of speech can also problematic. Some students might be misunderstood by the usage of "for" as a preposition and conjunction. This condition could end as giving the students a mental stress to differentiate the usage.

In the term of one-to-one principle, three of the coordinating conjunctions have more than one function. The "and" has four functions, "but" has three functions, and "or" even has six functions. Moreover, two different conjunctions even can be used to realize one single function, i.e. "so" and "for" which can be used to show reason. This condition is problematical in one-to-one principle in which one language form is usually only carry one meaning or function. In some way, the case of the "for" conjunction previously explained which also can be used as preposition is another example of one-to-one principle violation.

The length of exposure is another possible explanation of acquisition order phenomenon. It is stated that learners are able to learn morph syntactic structures quickly when the amount of exposure is in a constant level (Krashen, 2002, 2009; Moyer, 2004; Saville-Troike, 2006). When the exposure is given in a good way by means that the students get enough sample of language usage, the acquisition can be accelerated. This statement also has its position as one of the possible factors which can interfere the acquisition order.

Related to language exposure, it is also necessary to give the students a focus on forms language teaching of the meta-knowledge of language (Gass \& Selinker, 2008) which is English, in this case. It can be given intensively in classroom interactions ( Singleton, 2003; Krashen, 2009). The benefit of this action lies on giving the students' knowledge about how to use the language features appropriately, especially if the usage requires a pragmatic or discourse consideration. Again, to support this proposition, the use of authentic materials is recommended.

Based on the background of the study, two research questions are formulated to lead this research. Those questions are: 
1. What is the students' acquisition order of coordinating conjunction?

2. Why do the students acquire the coordinating conjunction in such order?

It is important to discover the students' coordinating conjunction acquisition order. Thus, the students' capacity in conjunctions' acquisition can be well-assessed. The information can be used by teachers to arrive at informed decision about techniques and/or materials selection in the teaching. The reason behind such order is also critical to be uncovered to come with the right attempt to counter balance the effect, if necessary.

\section{METHOD}

By employing quantitative and qualitative designs, 13 eleventh grade students were studied. Quantitatively, implicational scaling is used to answer the first research question that is to measure and determine the students' acquisition order of coordinating conjunctions. Meanwhile, qualitatively, case study method is employed to answer the second research question that is to discover the reason behind the phenomenon of such acquisition order.

Collecting the data related to the students' acquisition order, a test consist of 70 questions was given to the students. The questions are about the usage of seven coordinating conjunctions in which each of the words is represented by 10 questions. The corpuses used to compile the questions were taken from the students' textbooks and internet sources. The questions are divided into three different question types, namely (1) multiple choice, (2) fill in the blank, and (2) construction. The cut-off point was determined as in $50 \%$ of correct answer. It is a criterion in which test takers are categorized as either fit or does not fit the criterion concerned (McNamara, 2000; Richards \& Schmidt, 2002), and it is necessary to taken care seriously (Fulcher \& Davidson, 2007; Berry, 2008).

The data related to the explanation of students' acquisition pattern were collected through group interview and document analysis. Group interview was conducted to all of the students at a same time, and collected their shared understanding (Gay, Mills, \& Airasian, 2009) which is focused on revealing about the reason of their acquisition of one particular word which is faster than the others. Completing the data, document analysis on students' textbook was conducted to find out the frequency of each conjunction usage. This data is used to comprehend students' acquisition order in the relation with the exposure of the conjunction in the textbook.

The document analysis was done with a number of steps suggested by O'Leary (2014) along the process. First of all, a list of potential books was made in which then narrowed down into one book with two series. Second, considering the way of accessing the desired linguistic information in the book, 
it was decided that the books should be in form of pdf file. Third, developing appropriate way for searching the information, the "search" feature of a pdf reader software, Nitro PDF, was used. It gives the capability to the researcher to instantly locate the desired information in the books. Forth, ensuring the collected data is accurate, each words was contextually inspected to make sure that it was a conjunction rather than a preposition.

\section{FINDINGS}

\section{The Students' Coordinating Conjunction Acquisition Order}

The calculated data from the test were examined by employing implicational scaling to plot the pattern. The cut-off point is fixed in $50 \%$ since the usage of certain word for certain function in grammatical structure is considered as implicit knowledge (Ellis et al., 2009).

Table 2. Students' Coordinating Conjunction Acquisition Pattern

\begin{tabular}{|c|c|c|c|c|c|c|c|c|}
\hline$S$ & And & So & For & But & Or & Yet & Nor & \\
\hline 1 & 1 & 1 & 1 & 1 & 1 & 1 & 0 & \\
\hline 7 & 1 & 1 & 1 & 1 & 1 & 1 & 0 & \\
\hline 3 & 1 & 1 & 1 & 1 & 1 & 0 & 0 & \\
\hline 12 & 1 & 1 & 1 & 1 & 1 & 0 & 0 & \\
\hline 5 & 1 & 1 & 1 & 1 & 0 & 0 & 0 & \\
\hline 4 & 1 & 1 & 1 & 0 & 0 & 0 & 0 & \\
\hline 6 & 1 & 1 & 1 & 0 & 0 & 0 & 0 & \\
\hline 2 & 1 & 1 & 0 & 0 & 0 & 0 & 0 & \\
\hline 13 & 1 & 0 & 0 & 1 & 0 & 0 & 0 & \\
\hline 10 & 1 & 0 & 0 & 0 & 0 & 0 & 0 & \\
\hline 11 & 0 & 0 & 1 & 0 & 0 & 0 & 0 & \\
\hline 8 & 0 & 0 & 0 & 0 & 0 & 0 & 0 & \\
\hline 9 & 0 & 0 & 0 & 0 & 0 & 0 & 0 & \\
\hline Correct & 10 & 8 & 9 & 7 & 4 & 2 & 0 & 40 \\
\hline Errors & 0 & 0 & 1 & 1 & 0 & 0 & 0 & 2 \\
\hline
\end{tabular}


In the table 2, "1" means that the student's correct answers of the corresponded conjunction are $50 \%$ or more, and " 0 " means that the correct answers are below $50 \%$. By arranging the result according to the occurrence of the " 1 " value, a pattern of acquisition order emerges. There are two errors found in the data. Those are the " 1 " value for the "for" result of student number 11 , and the "but" result of student number 13 . The errors are determined to be ignored since the amount of the correct data outnumbers the error data.

Before the data can be used to make a pattern of acquisition order, the scalability of the data above should firstly be assessed. The calculation of the data scalability can be seen as follow.

$$
\begin{aligned}
& C_{\text {rep }}=1-\frac{\text { total number of error }}{(\text { number of } S s)(\text { number of items })} \\
& =1-\frac{2}{(13)(7)} \\
& =1-\frac{2}{91} \\
& =1-.021 \\
& =.979 \\
& M M_{\text {rep }}=\frac{\text { total correct }}{(\text { number of Ss })(\text { number of items })} \\
& =\frac{40}{(13)(7)} \\
& =\frac{40}{91} \\
& =.439 \\
& \% \text { improvement }=.979-.439 \\
& =.54 \\
& \text { Coefficient of scalability }=\frac{\% \text { improvement }}{1-M M_{\text {rep }}} \\
& =\frac{.54}{1-.439} \\
& =\frac{.54}{.561} \\
& =.962
\end{aligned}
$$


In order to be scalable, the coefficient must be above .60. From the calculation, the coefficient of scalability is .962 which is bigger than .60. The data then is considered as scalable and can be used to draw the coordinating conjunction acquisition order.

The table 2 explicitly states that the students' coordinating conjunction acquisition order is started from "and", and then followed by "so", "for", "but", "or", "yet", and "nor". The "and" conjunction is the most acquired coordinating conjunction which is acquired by 10 out of 13 students. The next most acquired coordinating conjunction is "so", which is acquired by eight out of 13 students. Then, "for" is the third acquired coordinating conjunction, which is acquired by seven out of 13 students. The forth acquired coordinating conjunction is "but", which is acquired by five out of 13 students. The fifth is "or", which is acquired by four out of 13 students, and the last is "yet" which is acquired by two out of 13 students. Meanwhile, the coordinating conjunction "nor" is not acquired by any students. It is then considered as the last conjunction acquired by the students.

To explain the students' conjunction acquisition order, further interviews were conducted to the students. The interviews use the result of the implicational scaling previously displayed to gather the information of potential cause of such order. It is important to study the data furthermore qualitatively to make sure the implicational scaling result can be explained which can be led to a potential solution of language teaching in conjunctions.

\section{The Possible Cause of the Acquisition Order}

The data from the group interview show that the students acquire "and" the most because they used it the most frequently in daily interaction. Meanwhile, the conjunction "nor" is not yet acquired because they never found it in their daily use. For the students, the test is the first time where they found the "nor" conjunction. The students' statement infers that the main problem in this case is the lack of exposure to the "nor" conjunction. It seems that the meaning or function of having a choice is enough to be stated with "or" conjunctions, so the teacher overlook the necessity to provide the students with another conjunction which provides another way to express a choice. Moreover, since the use of "nor" requires the presence of "neither", it is considered that "nor" is a complex conjunction compared to the others. It is in line with the formal complexity assumption that students will acquire the easiest one then move to the most complex one (Gass \& Selinker, 2008; Romaine, 2003). It is also in line with the fact that "and" is one of the most commonly used coordinating conjunction as stated by Shrives (2014). 
Additionally, the students stated that the teacher never teach them explicitly about conjunction or coordinating conjunction in classroom teaching activity. They only know about the coordinating conjunction in texts as it is used in the context, not learnt in explicit instructions. Based on the students' statements, it is suggested for the teacher to give more focus on the forms, in this case is meta-language knowledge, in classroom teaching activity (Gass \& Selinker, 2008). Knowledge about language forms is as important as the meaning itself. Without knowing what kind of form which can be used to communicate certain meaning, it would be hard for the students to have a seamless way of language use.

By the interview result, it seems that the teacher has already tried to provide the students with an authentic material. However, he was not in the position to teach the students about the conjunctions. Hence, the frequency of each conjunction is not well-managed. The texts used by the teacher appear to only use the most commonly used conjunction without any consideration to give a fair usage of all coordinating conjunctions. It is supported by the students' statement that they were never been taught about conjunction as a specific materials.

The data from document analysis also collected information related to another possible reason underlying the students' acquisition order of the conjunction. Two books with the title of Bahasa Inggris SMA Kelas XI for first and second semester published by KEMENDIKBUD in 2014 were analyzed to map the frequency of conjunctions used in the textbooks. The findings are shown in Table 3.

Table 3. Conjunction Exposure in the Textbooks

\begin{tabular}{|c|c|c|c|c|c|c|c|c|c|}
\hline \multicolumn{3}{|c|}{ Words count } & And & Or & But & So & for & yet & nor \\
\hline \multirow{3}{*}{ 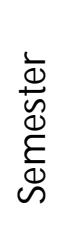 } & \multirow{3}{*}{-} & Prep. & - & - & - & - & 42 & - & - \\
\hline & & Conj. & 336 & 85 & 54 & 22 & 8 & 0 & - \\
\hline & & Other & - & - & - & 38 & - & 2 & - \\
\hline \multirow{3}{*}{ 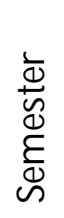 } & \multirow{3}{*}{$N$} & Prep. & - & - & - & - & 143 & - & - \\
\hline & & Conj. & 386 & 122 & 49 & 14 & 16 & 2 & 2 \\
\hline & & Other & - & - & - & 6 & - & 3 & - \\
\hline
\end{tabular}




\section{DISCUSSION}

Referring to the findings of the study investigating the students' acquisition order of coordinating conjunction, and the possible causes of such phenomenon, it can be discussed the research findings as follow.

Based on the findings, the "and" dominates the coordinating conjunction used in the textbooks, followed by "or", "but", "so", "for", "yet", and "nor". The "for" conjunction actually emerges in a quite high frequency. However, most of them are used as preposition, and only a small number of them used as conjunction. Then by looking into the materials presented in the textbook, the students in that level still do not get any learning materials about coordinating conjunction. It infers that the knowledge of coordinating conjunction is not explicitly taught by the teacher. Additionally, the book is also lack of equal exposure of each conjunction. It can be one of the reason of the occurred phenomenon which is clarified by Krashen (2002; 2009), Moyer (2004), and Saville-Troike (2006) who stated that learners are able to learn morph syntactic structures quickly when the amount of exposure is in a constant level.

From the result previously displayed, it can be concluded that not all of the external factors influence the order of the coordinating conjunction. From all four factors, only two factors which seem be able to alter the acquisition order of this case i.e. formal complexity and exposure factors. The factor of lexical marker has been forecasted to be not in the way of influencing the order since all of the coordinating conjunction is considered as lexical marker, not as grammatical marker. However, the one-to-one principle which seems to be highly influential appears to be out powered by the other factors. It can be seen that even when the "and", "or", and "but" carry more than one function, the students seems to be unproblematic to acquire those conjunctions.

The factors which appear to influence such order are the exposure and formal complexity. As the main reason, the students explicitly stated that they never see or hear anything about the "nor" conjunction before which makes them unable to acquire that conjunction. The analysis of the textbooks also come with a similar result that the "nor" conjunction appears only two times in the second semester book, and does not appear in the first semester book. Meanwhile, the formal complexity factor seems to only appear as a complementary factor which adds more explanation related to the complexity of the "nor" conjunction usage.

In this study, the exposure factor seems to overpower the one-to-one principle factor. Even when the "and", "or", and "but" carry more than one function, the high frequency appearance of those conjunctions seem to make the students acquire it unproblematically. The same reason is also can be used to explain the "so" and "for" which is also well-acquired by the students. By this 
finding, it can be stated that no mater hard or complex a language component is, an enough exposure could make it easier for the student to acquire.

Coordinating conjunction is necessary to be taught. It is the part of students' productive skill to organize ideas in dense and tidy form. The understating of coordinating conjunction might also help the students' comprehension in reading activity. Hence, the presentation of the conjunction is necessary in materials used in the classroom teaching activities, especially in textbooks. Each conjunction has its distinct meaning. Knowing the most common used coordinating conjunction may become the first step for the students in acquiring the conjunction. However, the other conjunctions which do not have a high frequency of usage should also be learnt since the students as academician will not only use it in a daily interaction, but also in a formal usage as in writing an academic paper.

If it is taken into the consideration of material authenticity, it seems that when the books pose as commercial materials. The amount of coordinating conjunction is not well-organized since it is not the materials the book writers want the students to learn. This rhetorical claim is supported by the result of analyzing the frequency of coordinating in the books analyzed in this study which shows that the usage frequency is not in a fair amount. One coordinating conjunction, "nor", even does not appear in the first semester book.

\section{CONCLUSION}

This study shows that the students' acquisition order of coordinating conjunction is started from "and" conjunction and followed by "so", "for", "but", "or", "yet", and "nor". This acquisition order is caused by several conditions. First, it is because the students found that the "and" conjunction is the most common used conjunction in daily activity, while "nor" conjunction is never being used for any of daily interaction. Second, the coordinating conjunction is never be taught explicitly in classroom activity. The last is related to the textbook used by the students. The presentation of those conjunctions in the textbooks are not well-developed. The analysis on the textbooks found that "and" conjunction is used about 722 times in both first and second semester books, meanwhile "nor" conjunction is only present for 2 times in both semesters. In brief, it is related to the matter of exposure and formal complexity.

This study has arrived at several suggestions. First, the teacher is suggested to teach about coordinating conjunction explicitly in classroom teaching and learning activities as in focus on forms language teaching. The implicit meaning of each conjunction seems to be hard be acquired unconsciously. Hence, a specific explanation is considered as necessary. If applicable, a focus on form language teaching where a language is learnt in an 
authentic communication can even give more meaningful language usage for the students. Then, in the case that the teacher want to use authentic materials, the appearance of the conjunction should be firstly assessed to make sure that the students receive a fair amount of each conjunctions.

Second, the textbook writers are suggested to consider to give ample exposures to the students related to the coordinating conjunctions. The presentation of all of the conjunction is important to give students ample knowledge about how each conjunction is used in the right context. Even if the coordinating conjunction is not the materials intended to be taught to the students, the existence of a full range conjunctions could be helpful for the students to get a better exposure of language sample. It is supported by the finding that even when some conjunctions are considered as hard to be acquired related to the one-to-one principle, it could be well-acquired when the exposure is managed to be enough.

When it comes to the beneficial contribution, this study takes a position as theoretical contributor and practical example. Theoretically, it confirms some claims that a number of coordinating conjunctions are used more frequent than the other. It also gives the scale in which the current teaching is supporting the trend of usage rather than fostering students to explore more variant ways of expressing ideas. Practically, the usage of implicational scaling should be comprehended as an alternative way of assessing students' comprehension. Teachers is suggested to use this method in order to map the students' knowledge in a more detailed way, so the teaching can be focused on the part the least students have acquired.

Further research is suggested to unearth the acquisition pattern of conjunction in general, not specified into one part of it as in this research. In alternative, the future researcher may study the other type of conjunctions for then is compiled with this study to draw a general conclusion of conjunction acquisition order and its possible cause.

\section{REFERENCES}

Berry, R. (2008). Assessment for learning. Hong Kong: Hong Kong University Press.

Ellis, R., Ioewen, S., Elder, C., Erlam, R., Philp, J., \& Reindrs, H. (2009). Implicit and explicit knowledge in second language learning, testing and teaching. UK: Multilingual Matters Ltd.

Farrokhi, F., \& Talabari, F. A. (2014). Focus on form instruction in EFL: Implication for theory and practice. Journal of English Language Teaching and Learning, 53(222), 29-47. 
Fauzi, I. (2012). The acquisition of WH-questions: A simple case in Indonesian children. Journal on English as a Foreign Language, 2(1), 1-10.

Fulcher, G., \& Davidson, F. (2007). Language testing and assessment: An advanced resource book. Abingdon, New York: Routledge.

Gass, S. M., \& Selinker, L. (2008). Second language acquisition: An introductory course (3rd Ed.). New York, NY: Taylor \& Francis.

Gay, L. R., Mills, G. E., \& Airasian, P. (2009). Educational research: Competencies for analysis and applications (9th Ed.). London: Pearson Education Limited.

Kachru, Y. (2005). Teaching and learning of world English. In Handbook of Research in Second Language Teaching and Learnin, 1, 11-44.

Krashen, S. D. (2002). Second language acquisition and second language learning. California: University of Southern California.

Krashen, S. D. (2009). Principles and practices in second language acquisition. California: University of Southern California.

Lengyel, Z., Navracsics, J., \& Szilagyi, A. (2007). Analysing L2 lexical processes via C test. In Z. Lengyel \& J. Navracsics (Eds.), Second language lexical processes. UK: Multilingual Matters Ltd.

Lieven, E., \& Tomasello, M. (2008). Children's first language acquisition from a usage-based perspective. In P. Robinson \& N. C. Ellis (Eds.), Handbook of cognitive linguistics and second language acquisition, 168-196.

McNamara, T. (2000). Language testing. Oxford: Oxford University Press.

Miftah, M. Z. (2016). Increasing EFL student's writing abilities using peer response activities via Facebook. Indonesian EFL Journal: Journal of ELT, Linguistics, and Literature, 2(2), 1-27.

Moyer, A. (2004). Age, accent, and experience in second language acquisition. UK: Multilingual Matters Ltd.

O'Leary, Z. (2014). The essential guide to doing your research project (2nd Ed.). Thousand Oaks, CA: SAGE Publications, Inc.

Richards, J. C., \& Schmidt, R. (2002). Dictionary of language teaching and applied linguistics (3rd Ed.). Malaysia: Pearson Education Limited.

Romaine, S. (2003). Variation. In C. J. Doughty \& Long (Eds.), The handbook of second language acquisition (pp. 409-435). UK: Blackwell Publishing Ltd.

Saville-Troike, M. (2006). Introducing second language acquisition. Cambridge, NY: Cambridge University Press. 
Shrives, C. (2014). What Are Coordinate (Coordinating) Conjunctions? (Grammar lesson). Retrieved May 24, 2015, from http://www.grammarmonster.com/glossary/coordinate_conjunctions.htm

Singleton, D. (2003). Critical period or general age factor(s)? In M. del P. G. Mayo \& M. L. G. Lecumberri (Eds.), Age and the acquisition of English as a foreign language (pp. 3-22). UK: Multilingual Matters Ltd.

Umami, M. (2011). The social context of early child second language acquisition (SLA). Register Journal, 4(2), 186-202.

\section{Author's Brief CV}

Deby Irawan is a master degree student at the Universitas Pendidikan Indonesia, Bandung, majoring in English for education at the time this article is submitted. His research interests and current publications are in the areas of culture issue in ELT materials, second language acquisition, and ICT-based teaching instructions. He is passionate in designing language teaching which accommodates students' condition in every way possible. He comes with the vision to ease the students learning process to accelerate their progress in acquiring language. 
